\title{
Fatores determinantes da inovação nas empresas agroindustriais de carne
}

\author{
Vanderlei José Sereia* \\ Eva Stal** \\ Marcia Regina Gabardo da Câmara ${ }^{* * *}$
}

\author{
Palavras-chave \\ inovação de produtos e \\ processos, agroindústria \\ de carne, fontes de \\ inovação, intensidade \\ tecnológica, exportações \\ Classificação JEL \\ $\mathrm{O} 14, \mathrm{O} 32$ \\ Keywords \\ product and process \\ innovation, meat \\ agribusiness, innovation \\ sources, technological \\ intensity, exports

\section{JEL Classification \\ O14, 032} \\ "Professor do Departamento de \\ Economia da Universidade Estadual \\ de Londrina (UEL), Londrina, PR. \\ "Professora do Programa de Pós- \\ Graduação em Administração da \\ FMU/SP, São Paulo, SP. \\ *** Professora do Departamento \\ de Economia e do Mestrado \\ em Economia - PPE/UEL da \\ Universidade Estadual de \\ Londrina (UEL), Londrina, PR.
}

\begin{abstract}
Resumo
O trabalho analisa os fatores determinantes de inovação em produtos e processos nas empresas agroindustriais de carne. A amostragem foi intencional, em 94 empresas brasileiras. A metodologia de natureza quantitativa e analítica. Utilizaram-se estatística não paramétrica, análise univariada, bivariada e testes de hipóteses. Foram testadas seis hipóteses na pesquisa empírica, realizada por levantamento, e a análise estatística confirma as hipóteses: as empresas são pouco inovadoras, a maioria faz inovação em processos mediante a compra de equipamentos modernos e ofertam novos produtos; as principais fontes de inovação são fornecedores, clientes, conferências, feiras e exposições. As grandes empresas são exportadoras, investem em inovação, adotam estratégia tecnológica ofensiva e usam recursos governamentais em P\&D. Conclui-se que o setor tem baixo potencial inovador, as transformações resultam de inovações incrementais, e as empresas inovadoras apresentam maior porte $\mathrm{e}$ potencial exportador.
\end{abstract}

\section{Abstract}

The paper analyzes the determinants of innovations in products and processes in agribusiness meat enterprises. The sample was intentional, from 94 Brazilian companies, and the methodology was of quantitative and analytical nature. We used nonparametric statistics, univariate and bivariate analysis, and hypothesis testing. Six hypotheses were tested in empirical research by survey, and statistical analysis confirmed them: firms are less innovative; most do process innovations, through the purchase of modern equipment, and offer new products; the main sources of innovation are suppliers, customers, conferences, fairs and exhibitions. Large companies are exporters, invest more in innovation, adopt offensive technological strategies and use government resources for $R \leftrightarrow D$. We concluded that the sector has low innovative potential, changes result from incremental innovations and innovative firms have larger size and export potential. 


\section{1_Introdução}

A indústria brasileira de processamento de carne é responsável pelo abastecimento interno e pelas crescentes receitas de exportação. A presença das empresas nacionais nos mercados mundiais tem estimulado mudanças na gestão, $\mathrm{e}$ a inovação permitiu construir a estratégia competitiva adequada para conquistar o mercado internacional.

Os principais produtores de carne são Estados Unidos, China, Brasil e União Europeia, responsáveis por $66,5 \%$ da carne de frango, $85 \%$ da carne suína e $61 \%$ da carne bovina. Conforme projeção da Organização das Nações Unidas para Agricultura e Alimentação (FAO, 2010), em 2030, o mundo precisará incrementar a produção de carnes em: 55\% de carne de frango, $47 \%$ de carne suína e $34 \%$ de carne bovina em relação à produção de 2010. Segundo o IBGE (2011), o Brasil é o maior exportador mundial de carne de frango e carne bovina, e o quarto de carne suína, e as exportações representam em média $22 \%$ da produção nacional.

No Brasil, a cadeia agroindustrial de carne é bastante estudada, mas a maioria dos trabalhos analisa os aspectos produtivos e as relações de mercado, verificando-se poucos estudos sobre inovação. O Brasil reúne ótimas condições para produzir carne, em termos de recursos naturais, clima e disponibilidade de terras, mas a disponibilidade inicial de fatores se traduz em vantagem estática para o país. Atualmente, as vantagens competitivas dinâmicas que influenciam o crescimento derivam de investimentos em inovação, posicionamento mercadológico e capacidade de exportação.

A Pesquisa de Inovação Tecnológica - PINTEC 2005 -, que analisa o período de 2001 a 2003, constatou que a indústria nacional de alimentos - que inclui as empresas agroindustriais de carne - apresentou baixa participação de empresas inovadoras: $32,5 \%$ das empresas realizaram inovação em produto e processo, a parcela do faturamento aplicada em atividades de inovação representou 1,5\%, e somente em
P\&D foi de 0,1\%. A PINTEC 2008, que analisa o período compreendido entre 2006 e 2008, verificou pequeno crescimento nos indicadores citados - 38,2\% das empresas realizaram inovações de processo e produto, a parcela aplicada a atividades de inovação subiu para 2,1\%, e os gastos com P\&D alcançaram 0,24\% do faturamento (IBGE, 2011). Todavia, empresas como JBS, Marfrig e Brasil Foods, líderes no segmento de carne, reagiram diante das concorrentes mundiais e se internacionalizaram, competindo com as grandes empresas mundiais pela liderança e pela participação no mercado mundial de carne. Segundo Stal, Sereia e Silva (2010), a inovação em produtos e processos revelou-se uma estratégia competitiva adequada para o diferencial das empresas nacionais no exterior.

Segundo a Organização para a Cooperação e Desenvolvimento Econômico (OCDE, 2005), em setores de média ebaixa intensidades tecnológicas, como a indústria de processamento de alimentos, têxteis e madeira, dentre outras, a inovação não é, em geral, baseada no conhecimento científico ou tecnológico mais recente. Frequentemente envolve experimentação interna e adaptação de tecnologias e aprendizagem não necessariamente baseadas em P\&D formal. Para Stal e Campanário (2010), tais indústrias também são usuárias das inovações geradas nas indústrias de alta tecnologia; porém, as empresas desses setores não são menos capazes de inovar do que as de alta tecnologia. A indústria de alimentos tem lançado sistematicamente novos produtos e se concentrado em produtos com menor teor de gordura. Conforme taxonomia desenvolvida por Pavitt (1984), indústrias de baixa e média tecnologias são dominadas pelos fornecedores, o que implica a adaptação de tecnologias adquiridas externamente em seus processos de inovação.

A utilização da abordagem neoschumpeteriana no presente estudo justifica-se porque essa corrente do pensamento 
econômico destaca a existência de uma dinâmica competitiva na qual a inovação é um elemento central de diferenciação entre as empresas. A abordagem fornece elementos para a discussão do processo evolutivo de firmas capitalistas destacando conceitos--chaves para a compreensão da dinâmica da firma e da economia: paradigmas e trajetórias tecnológicas; estratégias tecnológicas; rotinas, seleção e busca de inovações e processos de aprendizado (Dosi; Nelson, 1994).

Neste trabalho, estudam-se as motivações, as dificuldades e os fatores determinantes da decisão de inovar nas empresas do setor agroindustrial de carne e as estratégias de inovação utilizadas, seja mediante P\&D interna e/ou o acesso a fontes externas. Investigam-se as fontes preferenciais utilizadas pelas empresas e se busca relacionar os esforços de inovação a tamanho, origem do capital e ação exportadora das empresas. $\mathrm{O}$ objetivo do artigo é analisar os fatores que determinam a decisão de inovar em produtos e em processos e as fontes de inovação utilizadas pelas empresas agroindustriais de carne (frango, suína e bovina). $\mathrm{O}$ artigo está estruturado em cinco seções: introdução, revisão de literatura, metodologia, análise de resultados e notas conclusivas.

\section{2_Inovação: uma revisão da literatura}

A importância da inovação tecnológica para o desenvolvimento econômico dos países foi reconhecida, a partir de 1912, na concepção schumpeteriana, que a considerava a força propulsora da competitividade de empresas e países. A inovação é uma nova combinação de meios de produção que constitui um elemento central da economia. O sentido da inovação é transformar ideias em produtos, serviços e processos; para tanto, requer-se a organização de vários agentes que interajam para sua construção. Segundo Schumpeter (1984), o conceito de inovação tecnológica abrange a introdução de: novo produto, novo processo de produção, abertura de um novo mercado, conquista de uma nova fonte de insumo e estabelecimento de uma nova organização industrial.

Ao ser lançado o primeiro esforço inovador, outras empresas buscarão fazer o mesmo, na expectativa de terem maiores lucros ou forçadas pelo aumento da concorrência. Os investimentos em bloco decorrem da ação das rivais que induzem o crescimento econômico e, em grande medida, contribuem para a alteração da estrutura produtiva (Schumpeter, 1984). O processo de inovação tem três fases: invenção, inovação e difusão. A invenção caracteriza-se pela possibilidade de desenvolvimento de um produto ou um processo novo, mas que ainda não foi introduzido no mercado, ao passo que a inovação tem o significado puramente econômico, com base na comercialização de um produto novo ou na implantação de um processo novo. A difusão se refere à disseminação do conhecimento gerado ou da inovação em si.

A abordagem evolucionária neoschumpeteriana destaca a existência de uma dinâmica competitiva na qual a inovação é um elemento central de diferenciação entre as empresas. A abordagem fornece elementos para a discussão do processo evolutivo de firmas capitalistas destacando conceitos-chaves para a compreensão da dinâmica da firma e da economia: paradigmas e trajetórias tecnológicas; estratégias tecnológicas; rotinas, seleção e busca de inovações e processos de aprendizado (Dosi; Nelson, 1994).

De acordo com Dosi e Nelson (1994), a inovação refere-se à: busca, descoberta, experimentação, desenvolvimento, imitação e adoção de novos produtos, novos processos e nova organização. O processo de busca por inovações apresenta as seguintes características: dificuldade em prever o ritmo e a direção das inovações, derivado do grau de incerteza do processo inovador; existência de uma relação entre avanços científicos e avanços tecnológicos, garantia de maior confiança no resultado da busca tecnológica; as inovações são resultantes de pesquisas e investigações derivadas da 
busca de soluções de problemas, logo o desenvolvimento tecnológico depende de atividades incorporadas nas firmas; a ocorrência de aumento do número de inovações surge através de atividades formais e informais do conhecimento, como P\&D e as universidades; e o processo de mudança tecnológica acontece em função das características da própria tecnologia em uso que direcionam o processo de inovação. $\mathrm{O}$ conhecimento adquirido no passado orienta o comportamento e as transformações no futuro.

Segundo Possas (2008), em Nelson e Winter (1982), encontram-se os fundamentos de uma teoria evolucionária da economia e da firma, baseados na disseminação de rotinas eficientes; na busca e na adoção das inovações pelas firmas, e na seleção das firmas pelo mercado. As firmas que obtêm maior lucratividade e ampliam suas parcelas de mercado adotam rotinas mais adequadas. $\mathrm{O}$ processo de busca leva à adoção de inovações pela firma que tenha potencial para gerar rotinas indutoras de maior lucratividade, e as rotinas mais rentáveis tendem a ser adotadas no conjunto de rotinas da indústria, em um processo de seleção pelo mercado (Possas, 2008; Conceição, 2008). Há dois processos de seleção na abordagem de Nelson e Winter (1982): o processo da "seleção natural", que não é espontâneo, e o processo de seleção via aprendizado adaptativo. Os processos econômicos de mudança - mutação - envolvem os investimentos formais em P\&D - inovação -; e o esforço adaptativo, na forma de aprendizado, de natureza informal e não projetado (Possas, 2008).

Para Tidd, Bessant e Pavitt (2008), a inovação é um processo central da organização, relacionando-se à renovação da empresa, à sobrevivência e ao crescimento e envolve busca, seleção e execução. Nesse processo, desenvolve-se um aprendizado estabelecido pela interação entre as várias etapas do processo, desde a aquisição de conhecimen- tos à execução do projeto, ao lançamento do produto e à adoção e uso da inovação por um longo tempo.

As inovações podem ser classificadas em radicais ou incrementais. As inovações incrementais referem-se à introdução de qualquer tipo de melhoria dentro de uma empresa, sem alteração na estrutura industrial; estão relacionadas às demandas do mercado e às experiências do usuário. Embora sejam importantes para o aumento da produtividade, seus efeitos não introduzem mudanças estruturais na economia (Tigre, 2006). A inovação radical envolve o desenvolvimento e a introdução de outro produto, processo ou forma de organização da produção inteiramente nova, representando uma ruptura estrutural com o padrão tecnológico anterior, originando novas indústrias, setores e mercados.

O sucesso de uma inovação - e sua difusão na indústria - depende da definição dos problemas tecnológicos exigentes na indústria. A adversidade, a adaptação e a seleção são elementos importantes para a definição das estratégias empresariais e das trajetórias tecnológicas. As inovações tecnológicas adotadas pelas firmas podem alterar as estruturas econômicas e revelam a heterogeneidade nos processos de inovação e nas formas como as "firmas geram, utilizam, absorvem, desenvolvem e transferem tecnologias diferentemente uma das outras para a produção e produtos" (Arend; Cario; Erdele, 2012, p. 121).

Segundo Dosi (2006), paradigma tecnológico é um modelo ou um padrão de soluções de um conjunto de problemas de ordem técnica, selecionado com base no conhecimento científico e nas práticas produtivas. Ele representa um conjunto de prescrições que definem a direção das mudanças tecnológicas a serem seguidas e destaca aquelas que devem ser negligenciadas. Para Dosi e Nelson (1994), um paradigma tecnológico é caracterizado pela natureza do conhecimento tecnológico, que orienta a concepção das atividades inova- 
doras, bem como os procedimentos organizacionais, buscando e explorando inovações.

O paradigma tecnológico resulta em uma série de escolhas técnicas e econômicas que serão feitas pelas empresas, de acordo com as características do setor e do ambiente institucional onde elas se situam. Essas escolhas, ao estarem contidas num arcabouço técnico-produtivo, são reconhecidas como trajetórias tecnológicas e consideradas como atividade normal de solução de problemas técnicos conforme os padrões produtivos determinados pelo paradigma tecnológico vigente (Dosi, 2006). Assim, elas podem ser entendidas como a direção tomada pelo desenvolvimento tecnológico, uma vez que as empresas escolheram determinadas tecnologias visando a sua competitividade.

Para Malerba e Orsenigo (1996), as tecnologias se desenvolvem dentro de padrões inovativos (paradigmas), segundo as condições de oportunidade (opportunity), apropriabilidade (appropriabilitty) e cumulatividade (cumulativeness). As oportunidades tecnológicas estão relacionadas ao potencial de inovação de cada tecnologia e aumentam com os investimentos em P\&D; em geral, estão associadas a uma grande variedade de métodos e soluções técnicas. As inovações podem ser utilizadas em vários processos de produção.

A apropriabilidade relaciona-se à proteção das inovações contra imitações, com base no direito de propriedade, no segredo industrial, nas marcas e nas patentes. A possibilidade de retenção privada do conhecimento pode garantir mais lucro aos inovadores. Diferentemente dos setores com elevado grau de transbordamento ou de externalidade positivas, o processo de imitação é mais ativo.

A cumulatividade permite aos inovadores a possibilidade de inovações sequenciais tomando por base experiências em áreas correlatas. A acumulação de conhecimento facilita o desenvolvimento de inovações incrementais, que podem ser utilizadas em outros setores, além de potencializar a capacidade inovadora futura, comparada às concorrentes pouco experientes em inovações. $O$ processo de inovação cumulativo associa-se a ambientes tecnológicos com rendimentos crescentes das atividades de pesquisa.

As inovações nos diferentes setores da economia seguem trajetórias tecnológicas distintas, que consistem em possíveis direções do desenvolvimento. A noção de trajetória tecnológica emerge da observação de dependência de um caminho sinalizado pela estratégia das empresas, que pode ser igualmente aplicada a uma tecnologia, limitada pelo conhecimento científico, e a uma empresa, limitada pela sua capacidade (Tidd; Bessant; Pavitt, 2008). As trajetórias tecnológicas surgiram da observação de diferenças e similaridades marcantes em fontes de tecnologias e de direção das mudanças tecnológicas entre os setores industriais. $\mathrm{O}$ conhecimento da trajetória tecnológica de diferentes setores possibilita a escolha de estratégias tecnológicas mais adequadas para as empresas.

Pavitt (1984) desenvolve uma taxonomia calcada na mudança técnica para classificar os setores produtivos. A "taxonomia de Pavitt",em sua versão original, classificava os setores industriais em três categorias, conforme os padrões estruturais inovadores e tecnológicos prevalecentes: dominados por fornecedores; produção intensiva, que poderia ser intensiva em escala ou dominada por fornecedores especializados; e de base científica. Recentemente, foi realizada a inclusão da categoria de setores intensivos em informação (Tidd; Bessant; Pavitt, 2008).

De acordo com essa classificação, as empresas da agroindústria de carne se inserem, preferencialmente, na trajetória tecnológica do setor dominado por fornecedores de máquinas, equipamentos e insumos químicos e biológicos. As empresas do setor realizam baixo investimento em P\&D, dominam a inovação em processo, e sua absorção decorre da busca de redução de custo e do aumento da eficiência dos fatores. 
As empresas de setores dominados por fornecedores, a princípio, não contribuem substancialmente para o processo inovador, nem em relação à tecnologia de processo comprada fora, nem em relação aos produtos que, em geral, são de padrão tradicional ou de menor novidade. Elas possuem, porém, capacidade única com relação ao design. Uma modificação aplicada no processo produtivo da empresa pode ser executada e, mesmo que todas as máquinas e equipamentos sejam comprados de fornecedores, ainda pode haver espaço para atividade relacionada ao processo de inovação, como o design do sistema de produção, a abordagem dos recursos humanos e o desempenho do controle de qualidade (Christensen, 1995).

\section{- Estratégias tecnológicas na indústria de alimentos}

As técnicas de processamento e conservação de carne exigem base tecnológica avançada da biologia, da química e da microbiologia, que demandam pesquisas básicas e aplicadas, desenvolvidas em sua maioria por instituições públicas, como universidades e institutos de pesquisa. Para isso, dependem de investimentos públicos, de financiamentos em projetos privados e de cooperação. Segundo Santini (2006), a indústria de carne incorpora conhecimentos e importantes inovações desenvolvidas fora do setor, como na engenharia genética, mediante as técnicas de biologia molecular e tecnologias microeletrônicas, com importantes efeitos para o rendimento do processo e a qualidade dos produtos.

No processo produtivo, as mudanças são constantes pela introdução de outros insumos, equipamentos automatizados desenvolvidos por inovação em outras indústrias. As inovações de produto no setor agroindustrial de carne têm natureza incremental e são direcionadas à solução de controvérsias sobre sabor, textura, cor, rapidez e conveniência do consumo, qualidades nutricionais, possibilidades de conservação e facilidade na distribuição. As inovações em processos também são de natureza incremental, resultantes de acumulação de conhecimentos já existentes, como: a) adaptação de técnicas de conservação, de processamento em larga escala já conhecidas e de ampliação do conhecimento científico sobre as técnicas de conservação; e b) desenvolvimento de novas técnicas de conservação (irradiação e desidratação a frio), técnicas mais gerais e inovações de origem na P\&D (Santini, 2006).

Em geral, as empresas da indústria de carne adotam estratégias conservadoras, por serem dependentes de tecnologias desenvolvidas nos setores fornecedores de máquinas e equipamentos; de genética de animais; de vacinas e medicamentos; de insumos químico-minerais para complemento alimentar; e de rações. Apesar dessa dependência, há empresas que avançaram no processo de modernização e inovação, alcançaram escala de produção, criaram estruturas e desenvolveram habilidades técnicas internas que as capacitaram a ofertar produtos novos e diferenciados aos mercados nacional e internacional, como a Sadia e a Perdigão (unidas desde 2009 na Brasil Foods - BRF) e outras. Logo, as estratégias das empresas se transformam, em função do mercado crescentemente competitivo (Dalla Costa; Petit; Bittencourt, 2008).

As estratégias tecnológicas estão associadas aos objetivos dos dirigentes e dos acionistas da empresa. A escolha poderá incidir na busca de retornos do investimento no curto prazo ou na construção de uma base tecnológica para o futuro. As decisões dependem dos recursos financeiros e humanos, das características do mercado, da dinâmica tecnológica do setor e da estratégia geral da empresa. Segundo Tigre (2006) e Freeman e Soete (2008), as empresas buscam superar as incertezas de mercado, adotando uma ou mais das seguintes estratégias.

A estratégia ofensiva tem como objetivo atingir a liderança tecnológica e de mercado e viabiliza-se com a intro- 
dução de outros produtos, outros processos, outros modelos de negócios, na forma de prestação de serviços, no modo de relacionamento com o cliente, na logística de distribuição ou no desenvolvimento de design original. A estratégia ofensiva exige que a empresa tenha muito boa capacidade técnica e criativa, interna e externa, com acesso a laboratórios e centros de pesquisa, e boas relações com consultores e fornecedores. As tecnologias podem ter origem em várias fontes e resultar da combinação de vários elementos e pacotes tecnológicos (Freeman; Soete, 2008).

A estratégia defensiva é adotada pela maioria das empresas - principalmente aquelas que operam em mercados oligopolistas - e está associada à diferenciação de produtos. Tais empresas são altamente intensivas em pesquisa, dão importância considerável às patentes, buscam maiores lucros para cobrir os altos custos de P\&D, possuem visão de longo prazo e estão preparadas para correr altos riscos. As empresas de biotecnologia são exemplos do uso intensivo de P\&D e agressividade na geração de inovação, fazendo frente às grandes corporações na competição por mercados (Freeman; Soete, 2008).

A estratégia defensiva difere da estratégia ofensiva e visa reduzir o risco, mas aumenta a possibilidade de perder participação de mercado. No que se refere ao tempo de lançamento da inovação de produto, a empresa terá oportunidade de oferecer, mais tarde, o produto em condição mais vantajosa que seu concorrente. No caso de uma empresa intensiva em pesquisa, ela estará apta a reagir prontamente à iniciativa inovadora do concorrente (Stal, 2007).

A estratégia imitativa é adotada pelas empresas que não aspiram a ser líderes ou a ter grandes lucros, oferecendo um produto semelhante aos existentes e de menor custo. Verifica-se essa estratégia em mercados onde não há presença direta de empresas inovadoras. Quando é integrada verticalmente, a empresa também pode assegurar um mercado cativo, porém defasado tecnologicamente. Outra forma de assegurar o mercado é através do acesso privilegiado a canais de distribuição. As fontes de tecnologias utilizadas pelas empresas que adotam essa estratégia são as licenças de fabricação, a engenharia reversa ou a simples cópia do produto no mercado (Tigre, 2006).

As estratégias dependentes são utilizadas pelas empresas subordinadas a empresas mais fortes. Elas tomam a iniciativa de inovar por demanda explícita de seus clientes ou de seus controladores e dependem de outras empresas para obter as instruções técnicas. A estratégia tradicional é usada pelas empresas que praticamente não mudam seus produtos ao longo do tempo, uma vez que a demanda de mercado não exige, e os concorrentes também não inovam. Finalmente, há as empresas que buscam oportunidades temporárias ou nichos de mercado não preenchido pela concorrência, que não requeiram grande investimento em pesquisa. Elas conseguem prosperar em nichos de mercado que não são aparentes para a maioria das empresas (Tigre, 2006).

\section{- Instrumentos de apoio à política de inovação}

A pesquisa e o desenvolvimento científico nos países avançados sempre foram de responsabilidade política do governo central, por serem consideradas atividades de elevado risco. No Brasil, não é diferente; essa preocupação é verificada pela existência de órgãos como o Conselho Nacional de Desenvolvimento Científico e Tecnológico (CNPq), a Financiadora de Estudos e Projetos (Finep) e o Banco Nacional de Desenvolvimento Econômico e Social (BNDES), que agem na condução da política de financiamento e desenvolvimento da C\&T. Por outro lado, a política industrial sempre garantiu liberdade às empresas para licenciar tecnologias estrangeiras, o que levou ao distanciamento entre as empresas e as universidades e as instituições de pesquisa (Sbragia et al., 2006). 
O Brasil dispõe, atualmente, de um conjunto bastante abrangente de mecanismos de apoio ao desenvolvimento tecnológico nas empresas; no entanto, o próprio governo tem dificuldades para operar esses instrumentos. Por outro lado, o setor produtivo se mostra lento em engajar-se no processo. Além disso, tais instrumentos por si sós não induzem o setor privado à realização de $P \& D$ e à inovação. Eles servem de apoio às iniciativas empresariais ao reduzir os custos e os riscos da P\&D e da inovação (Veiga; Rios, 2011).

O Ministério da Ciência, Tecnologia e Inovação (MCTI) tem como principal desafio romper com o atraso tecnológico em alguns setores da economia nacional. Com esse objetivo, busca fortalecer as ações das agências CNPq, Finep e BNDES, para o apoio à inovação nas empresas, e promover a aproximação dessas com as instituições geradoras de tecnologias, por meio da concessão de incentivos fiscais às empresas de informática e automação, e às empresas que realizam atividades de P\&D em qualquer setor industrial, de financiamento e do uso de recursos dos fundos setoriais com vistas a financiar projetos de $\mathrm{P} \& \mathrm{D}$ em cooperação entre as universidades e as empresas (Finep, 2011).

O BNDES, a partir de 2004, procurou suprir o crédito complementar aos recursos da Finep, ao criar duas linhas de apoio à inovação: a) Capital Inovador, destinado ao plano de investimento em inovação nas empresas; b) Inovação Tecnológica, direcionada a projetos de inovação tecnológica que envolvam risco e oportunidades de mercado. Atualmente, o banco disponibiliza linhas de financiamento de longo prazo, subscrição de valores mobiliários e prestação de garantias, atuando por meio de produtos, fundos e programas. Os mecanismos de apoio à inovação são ofertados por linhas de financiamentos a projetos de implantação, expansão e modernização de empreendimentos das empresas (BNDES, 2011).

A Lei de Inovação (Lei no 10.973/2004) dispõe de incentivos à inovação e às pesquisas científica e tecnológica. Embo- ra não ofereça recursos diretos, ela serve de base para ações de diversas leis federais e de incentivos à $\mathrm{P} \& \mathrm{D}$ (Finep, 2011). Os principais incentivos que a lei prevê são: a) cooperação, envolvendo empresas nacionais, Institutos de Ciência e Tecnologia (ICTs) e órgãos de direito privado sem fins lucrativos voltados para atividades de pesquisa e desenvolvimento, com o objetivo de gerar produtos e processos inovadores; b) regulamentação da participação das ICTs públicas em projetos de cooperação, normatizando-se aspectos como propriedade intelectual e transferência de tecnologia; e c) estímulo à inovação nas empresas, particularmente com a concessão de subvenção econômica.

A criação dos fundos setoriais também estabeleceu prioridades na política de inovação e disciplinou o uso de recursos públicos não reembolsáveis a atividades empresariais de $\mathrm{P} \& \mathrm{D}$. Atualmente são 16 fundos setoriais gerenciados pela Finep, dos quais 14 se referem a setores específicos e dois são transversais. Destes, o Fundo Verde-Amarelo é voltado para a integração entre universidade e empresa, ao passo que o outro se propõe a apoiar a melhoria da infraestrutura dos Institutos de Ciência e Tecnologia (ICTs). Os fundos setoriais são direcionados às seguintes áreas: Audiovisual, Aeronáutico, Agronegócio, Amazônia, Transporte Aquaviário e Construção Naval, Biotecnologia, Energia, Espacial, Recursos Hídricos, Tecnologia da Informação, Mineral, Petróleo e Gás Natural, Saúde, Transportes Terrestres e de Desenvolvimento Tecnológico das Telecomunicações (Finep, 2011).

Os principais mecanismos do governo brasileiro de apoio à inovação nas empresas são os incentivos fiscais e as subvenções econômicas previstas na Lei no 11.196/2005, que ficou conhecida como "Lei do Bem", e no Decreto ${ }^{\circ}$ 5.798/2006, que incluem: a) dedução do imposto de renda de $160 \%$ a $200 \%$ sobre as despesas com P\&D próprias ou contratadas; b) redução de 50\% de IPI, na aquisição de equipamentos destinados às atividades de P\&D; c) depreciação acelerada 
de tais equipamentos; d) amortização acelerada em aquisições de bens intangíveis para atividades de P\&D; e) crédito do imposto de renda retido na fonte de remessa ao exterior relativa a royalties, assistência técnica ou serviços especializados; f) subvenção ou ressarcimento de parte do valor da remuneração de pesquisadores mestres ou doutores que venham a ser contratados pelas empresas, em atividades de inovação (Grizendi, 2011). As empresas não precisam enviar os projetos para as agências, já que a "Lei do Bem" dispensa a autorização prévia para a utilização dos incentivos.

\section{- Fontes externas e internas de inovação}

Para Rodrigues, Vasconcellos e Sbragia (2007), as empresas brasileiras estão descobrindo que o processo de inovação tecnológica no âmbito global é muito complexo, visto precisarem atender às necessidades de produtos e processos de consumidores locais e estrangeiros. Não basta pensar apenas em fazer melhorias e adaptação em produtos, processos e serviços; é preciso ainda inventar e inovar para atender aos diferentes mercados. Para isso, estão conduzindo suas atividades em P\&D de forma global, visando maior proximidade com o mercado, maior acesso a tecnologias e a know-how, mediante parcerias com fornecedores, competidores, universidades e pesquisadores de talento.

Segundo os autores, as empresas que visam atender aos requisitos de conhecimentos necessários ao desenvolvimento de novos produtos e processos e acompanhar a tendência do consumo buscam fazer arranjos cooperativos, como as alianças estratégicas, para obter acesso à tecnologia onde ela estiver disponível. Nenhuma empresa consegue, isoladamente, desenvolver todas as competências para o desenvolvimento de produtos e processos inovadores. Todavia, o esforço das empresas em transformar tecnologias geradas no exterior tem esbarrado na característica tácita do conhecimento tecnológico, que exige dos pesquisadores certa interação que os capacite à troca de informações e ideias (Lall, 2005). Por essa razão, muitas empresas não têm condições de acessar diretamente a tecnologia gerada no exterior. Dada tal limitação, elas procuram aproximação com as universidades e os institutos de pesquisa e fazem alianças estratégicas para facilitar o acesso e o desenvolvimento conjunto de tecnologias.

Segundo Sbragia et al. (2006), as fontes de inovação podem ser resumidas em quatro grupos distintos: fontes internas às empresas, fontes relacionadas ao mercado de insumos e produtos da empresa, fontes de domínio público e fontes variadas. As fontes internas não são exclusividade do departamento de $\mathrm{P} \& \mathrm{D}$; elas podem surgir de vários departamentos da empresa, geralmente aqueles mais relacionados à criação e ao design do produto, como os departamentos de Engenharia, Marketing e até mesmo o de Produção.

As fontes relacionadas ao mercado de insumos e produtos, que a empresa processa na sua atividade produtiva, são os fornecedores, os clientes e os concorrentes da empresa. Por outro lado, também se registra a inovação pela aquisição de equipamentos e pela engenharia reversa dos produtos-alvos para a empresa.

As fontes do domínio público relacionam-se com a difusão do conhecimento gerado e disseminado pela sociedade, como os periódicos acadêmicos e as teses. Outras formas muito utilizadas são os congressos científicos e as feiras e exposições nacionais e internacionais, abertas à comunidade de interessados. Uma quarta fonte de inovação é caracterizada por informação e conhecimento propiciado por universidades, instituições de pesquisa e centros de capacitação públicos ou privados, empresas de consultoria, licenciamento de patentes e aquisições de know-how.

Segundo Tidd, Bessant e Pavitt (2008), as empresas buscam inovações em fontes externas por vários motivos, dentre os quais se destaca a necessidade de reduzir custos e riscos para o desenvolvimento de tecnologias, a entrada mais 
rápida no mercado, a obtenção de economias de escala na produção e a redução de tempo para o desenvolvimento e a comercialização de novos produtos. A utilização de fontes externas de tecnologia em cooperação pode trazer benefícios importantes, como o estímulo à revisão de funções da P\&D, o aumento da aceitação de ideias externas, o estímulo aos pesquisadores da empresa para desenvolverem novas ideias e diferentes perspectivas de pesquisas.

Andreassi (2007), utilizando dados da ANPEI, constatou que as empresas brasileiras estão se concentrando em duas formas distintas de obter tecnologias: na compra de tecnologia ou no esforço por desenvolver inovação internamente, embora a literatura reconheça o melhor resultado pelo uso combinado dessas duas iniciativas.

Pesquisa realizada pela Fapesp em 2005 identificou as contribuições das diferentes fontes de inovação na indústria paulista e verificou que a contribuição de outras áreas da empresa foi considerada de alta relevância. $O$ índice de avaliação do departamento de P\&D foi considerado de baixa importância por grande parte das médias e das pequenas empresas, e as fontes de inovação são o mercado de insumos e produtos, valendo-se de informações de fornecedores, clientes e concorrentes (Sbragia et al., 2006). Nas fontes públicas de inovação, os artigos acadêmicos, as teses e os eventos científicos ganharam a preferência dos empresários (30\%), e as feiras e exposições (20\%) são as principais fontes de inovação. As "fontes variadas de informações para inovação" foram mencionadas por apenas $5 \%$ das empresas, 0 que significa que uma pequena parte delas prefere buscar a informação nos institutos de pesquisa, em universidades, nas empresas de consultoria e informações disponíveis no licenciamento de patentes, consideradas como fontes complementares de conhecimento para o processo de inovação na empresa.

\section{3_Procedimentos metodológicos}

A pesquisa tem uma abordagem quantitativa descritiva, utilizando-se o método survey (levantamento), de corte transversal, mediante questionário estruturado aplicado às empresas agroindustriais processadoras de carne, via internet. As fontes de dados têm duas origens. A primeira utiliza dados levantados no IBGE, e em sites das próprias empresas, associações de classe e sindicatos que reúnem as empresas agroindustriais de carne. A segunda fonte é a pesquisa de campo, onde as informações foram obtidas de executivos (diretores ou gerentes) indicados pelas empresas. $O$ questionário foi enviado pela internet com instruções para o preenchimento online e devolução. Optou-se pelo levantamento por correspondência, utilizando-se a internet, em razão da grande dispersão geográfica das empresas. Dúvidas foram esclarecidas em contato com os respondentes via telefone e correio eletrônico.

\section{- Universo da pesquisa e seleção da amostra}

A produção e as exportações brasileiras de carne estão concentradas nos seguintes estados: Paraná, Santa Catarina, Rio Grande do Sul, São Paulo, Minas Gerais, Goiás, Mato Grosso e Mato Grosso do Sul. Esses estados são responsáveis por 99,5\% das exportações e por $85 \%$ da produção nacional (IBGE, 2011). Assim, decidiu-se formar a amostra da pesquisa com essas empresas.

O universo do estudo é formado pelas empresas agroindustriais processadoras de carne filiadas às associações de classe, além da inclusão de empresas listadas na revista Exame (Melhores \& Maiores, 2010) e no Anuário do Comércio Exterior (2010), e outras registradas em associações e sindicatos estaduais de avicultores e na internet. Mediante buscadores, utilizaram-se palavras-chave como "agroindústria de carne", "frigoríficos", "abatedouros", dentre outras, formando-se a lista de 439 empresas. Por contato telefônico, foram localizadas 290 empresas. Das empresas contatadas, 
retornaram 113 questionários, e, desses, 94 foram considerados válidos.

O método de amostragem utilizado foi não probabilístico (conveniência), pela dificuldade de identificar todas as empresas do setor de carnes no Brasil. A pesquisa se processou com apoio de um formulário eletrônico, fácil de preencher e de custo reduzido. O questionário e o link de acesso foram enviados aos executivos. Durante o período definido para o levantamento, de setembro a outubro de 2011, foi realizado acompanhamento complementar por e-mail e telefone.

Para análise de dados, foi utilizado o método de estatística descritiva e inferencial (análise univariada e bivariada). Foram realizados testes de significância (não paramétricos) para testar algumas hipóteses - nem todas puderam ser testadas, e, nesses casos, a estatística descritiva prevaleceu. Os testes não paramétricos têm como vantagens a sua utilização em populações que não tenham distribuição normal e a sua adequação a amostras pequenas (Siegel; Castellan, 2006).

O teste qui-quadrado $\left(X^{2}\right)$ foi empregado para distinguir frequências das variáveis observadas das frequências esperadas na amostra. Para permitir a sua realização, juntamos algumas categorias, para que as células tivessem valores iguais ou superiores a cinco casos, o que ocorreu com as análises resultantes dos dados de algumas tabelas.

\section{- Hipóteses e pressupostos de pesquisa}

As duas primeiras hipóteses foram formuladas com base nos trabalhos de Nonnenberg (2011) e De Negri (2005), que mostram existir forte correlação entre a decisão de exportar, os gastos em P\&D e o crescimento da produtividade.

H1- Existe relação positiva entre investimentos em inovação e exportações.

\section{H2- Grandes empresas do setor investem mais em inovação do que empresas médias e pequenas.}

A terceira hipótese refere-seà utilização deinstrumentos governamentais de apoio à inovação, por parte das empresas, e sua influência sobre os resultados obtidos. No Brasil, a pesquisa e o desenvolvimento tecnológico são apoiados pelos governos (federal, estaduais e, às vezes, municipais), por constituírem atividade de risco. Órgãos como o Conselho Nacional de Desenvolvimento Científico e Tecnológico (CNPq), a Financiadora de Estudos e Projetos (Finep) e o Banco Nacional de Desenvolvimento Econômico e Social (BNDES) conduzem programas de apoio à inovação, sob a orientação do Ministério da Ciência, Tecnologia e Inovação (MCTI). Além de financiamentos com juros reduzidos, existem incentivos fiscais para as empresas que investem em P\&D, por meio da "Lei do Bem", de 2005, e da "Lei da Inovação", de 2004.

Os novos instrumentos, por si sós, não induzem à realização de $P \& D$ e inovação, servindo de apoio às iniciativas empresariais na redução dos custos e riscos das atividades de P\&D. A hipótese teve como base os resultados da PINTEC 2005 e da PINTEC 2008, que revelaram aumento no número de empresas que fizeram uso desses instrumentos no período da pesquisa.

H3- Existe relação positiva entre contar com apoio financeiro governamental e o desenvolvimento de inovações de produto e processo.

A quarta hipótese refere-se às estratégias tecnológicas escolhidas pelas empresas agroindustriais de carne, aos resultados pecuniários e aos tipos de inovação. Como os mercados estão cada vez mais competitivos, exige-se das empresas maior agilidade na oferta de novos produtos que despertem a atenção dos clientes. Segundo Freeman e Soete (2008), as estratégias tecnológicas são definidas considerando-se sua maior ou menor agressividade no desenvolvimento de novos produtos e são classificadas em ofensivas (a mais agressiva), 
defensivas, imitativas, dependentes, tradicionais e oportunistas. Com base nesses autores, procura-se verificar se a estratégia tecnológica está associada à estratégia competitiva da empresa e também ao dinamismo do setor e à estrutura de concorrência, dentre outros fatores.

\section{H4- Existe relação positiva entre a estratégia tecnológica ofensiva da empresa e a sua ação exportadora.}

A quinta hipótese está relacionada aos tipos de inovação - de produto ou de processo. De acordo com a classificação de Tidd, Bessant e Pavitt (2008), as empresas estudadas constituem um setor dominado por fornecedores, e grande parte das inovações de produto é resultado de inovações no processo produtivo, ou seja, pelo investimento em equipamentos e bens de capital, os quais são específicos de determinadas atividades na rotina de produção. A inovação no setor agroindustrial de carne é predominantemente incremental e está relacionada às limitações da procura e ao comportamento conservador do consumidor (Capitanio; Coppola; Pascucci, 2009).

\section{H5- A inovação nas empresas agroindustriais de carne é mais frequente em processos do que em produtos.}

A sexta hipótese refere-se à decisão de desenvolver a inovação internamente ou combinada com atividades externas, em cooperação com outras organizações. À medida que aprofundam suas atividades inovadoras, as empresas necessitam de estrutura adequada que possa internalizar as tecnologias e as inovações acessadas. Os custos elevados e a redução do ciclo de vida dos produtos dificultam o desenvolvimento apenas interno de pesquisa para gerar tecnologias. A estratégia de usar a estrutura interna de $\mathrm{P} \& \mathrm{D}$ em conjunto com ações de cooperação visa potencializar os recursos disponíveis, proporcionando o contato direto de pesquisadores e desenvolvendo uma rede de discussões técnicas, melho- rando a capacitação técnica interna, em conformidade com a ideia de inovação aberta de Chesbrough (2003).

H6- As empresas mais inovadoras se apoiam mais em fontes externas de inovação.

Dentre as limitações do trabalho, apontam-se a amostra por conveniência e a abrangência geográfica do estudo, fator este que dificultou a localização das empresas, sendo possível identificar apenas as maiores, as que possuem marcas mais conhecidas e as que têm endereço eletrônico na internet. Grande parte das empresas contatadas não respondeu à pesquisa.

\section{4_Análise de resultados}

As 94 empresas agroindustriais de carne estudadas exploram atividades relacionadas à carne de frango, à carne suína e à carne bovina. Em sua maioria (74,5\%), trabalham com um único tipo de carne, e as demais combinam dois ou três tipos. Quanto à origem e ao controle do capital, é majoritário (95,8\%) o capital nacional e diminuta a presença do capital estrangeiro e do capital misto (4,2\%), refletindo a sua distribuição no setor.

Ao tentar relacionar esses tipos de atividade com a realização de inovações, os grupos ficaram muito pequenos, inviabilizando várias análises. Assim, foi decidido tratar todas as empresas como um só grupo - produtoras/processadoras de proteína animal. Para fins de análise, as empresas foram estratificadas pelo porte, considerando-se o faturamento bruto, segundo a classificação do BNDES: microempresa, até $\mathrm{R} \$ 2,4$ milhões; pequena empresa, de $\mathrm{R} \$ 2,4$ milhões a $\mathrm{R} \$ 16,0$ milhões; média empresa, de $\mathrm{R} \$ 16,0$ milhões a $\mathrm{R} \$ 90,0$ milhões; média-grande empresa de $\mathrm{R} \$ 90,0$ milhões a $\mathrm{R} \$ 300,0$ milhões, e grande empresa, acima de $\mathrm{R} \$ 300,0$ milhões. Na presente amostra, não há microempresas. 
Tabela 1_Porte das empresas e média de empregados, faturamento, exportações e investimentos em inovação - (em R\$ mil)

\begin{tabular}{|c|c|c|c|c|c|}
\hline Porte & Empresas & Empregados & Faturamento & Exportações & Investimento \\
\hline Pequenas & 17 & 79 & $4.508,60$ & & 60,5 \\
\hline Médias & 10 & 275 & $54.362,00$ & $3.337,50$ & 291,2 \\
\hline Médias-Grandes & 28 & 821 & $183.411,60$ & 72.263,30 & 720,4 \\
\hline Grandes & 39 & 6.764 & $1.843 .965,9$ & $555.366,90$ & $3.615,80$ \\
\hline Total & 94 & 290.836 & 77.667.759,00 & 23.716.088,00 & $165.130,00$ \\
\hline
\end{tabular}

Fonte: Dados da pesquisa de campo dos autores.

A Tabela 1 apresenta o perfil das empresas pelo porte. $\mathrm{O}$ aumento do porte da empresa eleva o número de empregados, o valor do faturamento, das exportações e do investimento em inovação. Posto que a atividade de exportação seja comum entre as médias-grandes e as grandes empresas, as pequenas empresas não exportam, ao passo que algumas médias empresas o fazem.

Embora seja não probabilística, a amostra de pesquisa é representativa do setor agroindustrial pecuário. Segundo o IBGE (2011), o faturamento desse setor em 2010 foi de 121,278 bilhões de reais, enquanto o faturamento das empresas da amostra de pesquisa representa $64 \%$ desse setor. Já as cinco maiores empresas da amostra faturaram 46,929 bilhões de reais, o equivalente a $60,4 \%$ do faturamento da amostra e $38,7 \%$ do faturamento do setor pecuário brasileiro.

\section{- Testes de hipóteses da pesquisa}

As hipóteses de pesquisa foram testadas utilizando-se as técnicas de análise descritiva, a relação entre variáveis, a determinação de frequência, a diferença entre médias e os testes não paramétricos. A hipótese $H_{1}$ foi formulada na frase "Existe relação positiva entre investimentos em inovação e exportações", sendo realizado o cruzamento entre as variáveis "exportações" e "investimentos em inovação". A Tabela 2 apresenta a condição da empresa (exportadora e não exportadora), e o investimento em inovação em per-
Tabela 2_Condição da empresa e investimento em inovação

\begin{tabular}{|c|c|c|c|c|c|c|}
\hline \multirow[t]{2}{*}{ Empresa } & \multicolumn{2}{|c|}{$\begin{array}{l}\text { Até } 0,25 \% \text { do } \\
\text { faturamento }\end{array}$} & \multicolumn{2}{|c|}{$\begin{array}{l}\text { Acima de } 0,25 \% \\
\text { do faturamento }\end{array}$} & \multirow[b]{2}{*}{ Total } & \multirow[b]{2}{*}{$\%$} \\
\hline & Empresa & $\%$ & Empresa & $\%$ & & \\
\hline Exportadora & 39 & 97,5 & 31 & 57,4 & 70 & 74,5 \\
\hline Não exportadora & 1 & 2,5 & 23 & 42,6 & 24 & 25,5 \\
\hline Total & 40 & 100 & 54 & 100 & 94 & 100 \\
\hline
\end{tabular}

Fonte: Dados da pesquisa de campo dos autores.

centual do faturamento bruto. As exportadoras constituem $74,5 \%$ das empresas que investem em inovação; dessas, $41,5 \%$ investem no máximo $0,25 \%$ do seu faturamento bruto. As empresas não exportadoras representam $25,5 \%$ da amostra, e a maioria delas investe mais de $0,25 \%$ de seu faturamento.

Verifica-se que as empresas não exportadoras são pequenas (menor faturamento) e as empresas exportadoras são médias-grandes e grandes (alto faturamento); também é possível verificar o efeito das inovações sobre a condição exportadora das empresas (Tabela 2). 0 maior número de empresas não exportadoras que investem acima de 0,25\% de seu faturamento em inovação significa, em termos relativos, que seu esforço inovador é maior que o das exportadoras. Em termos absolutos, o valor do investimento em inovação das empresas exportadoras é superior ao investido pelas empresas não exportadoras, dado seu enorme faturamento. Os valores indicam existir forte associação 
Tabela 3_Relação entre porte da empresa e investimento médio em inovação

\begin{tabular}{|c|c|c|c|c|c|c|}
\hline \multirow{2}{*}{ Porte das empresas } & \multicolumn{2}{|c|}{ Até $0,25 \%$ do faturamento } & \multicolumn{2}{|c|}{ Acima $0,25 \%$ do faturamento } & \multicolumn{2}{|l|}{ Total } \\
\hline & Empresas & Média (R\$ mil) & Empresas & Média ( $\mathrm{R} \$$ mil) & Empresas & Média (R\$ mil) \\
\hline Pequena & 0 & 0 & 17 & 60,5 & 17 & 60,5 \\
\hline Média & 1 & 115 & 9 & 310,8 & 10 & 291,2 \\
\hline Média-Grande & 14 & 235,5 & 14 & $1.205,40$ & 28 & 720,4 \\
\hline Grande & 25 & $3.397,20$ & 14 & $4.006,30$ & 39 & $3.615,80$ \\
\hline Total & 40 & 2.208,50 & 54 & $1.422,00$ & 94 & $1.776,70$ \\
\hline
\end{tabular}

Fonte: Dados da pesquisa de campo dos autores.

Tabela 4_Inovação e o porte das empresas

\begin{tabular}{|c|c|c|c|c|c|c|}
\hline \multirow{2}{*}{ Tipos de inovação } & \multicolumn{2}{|c|}{ Pequenas e médias empresas } & \multicolumn{2}{|c|}{ Médias-grandes e grandes empresas } & \multicolumn{2}{|l|}{ Total } \\
\hline & Empresas & {$[\%]$} & Empresas & {$[\%]$} & Empresas & {$[\%]$} \\
\hline Inovação de produto & 5 & 50,0 & 5 & 50,0 & 10 & 100 \\
\hline Inovação de processo & 22 & 26,2 & 62 & 73,8 & 84 & 100 \\
\hline Total & 27 & 28,7 & 67 & 71,3 & 94 & 100 \\
\hline
\end{tabular}

Qui-quadrado $=2,474=0,116$

Fonte: Dados da pesquisa de campo dos autores.

entre o investimento em inovação e a condição exportadora da empresa. De acordo com a Tabela 3, as empresas inovadoras e as exportadoras têm o valor médio de investimentos em inovação 14,9 vezes maior do que o das empresas não exportadoras. Portanto, confirma-se a hipótese $\mathrm{H}_{1}$ de que existe relação positiva entre investir em inovação e exportar.

Hipótese H2: "Grandes empresas do setor investem mais em inovação do que empresas médias e pequenas". Esta hipótese foi testada pela técnica de associação e pela comparação de médias entre as variáveis, o porte das empresas e os investimentos em inovação.

É maior o grupo de empresas que investem mais de 0,25\% do seu faturamento em inovação (54). Observa-se que o investimento médio em inovação é crescente à medida que aumenta o tamanho das empresas. Pode-se afirmar que as pequenas e as médias empresas fazem maior esforço para inovar, pois, com exceção de uma, as demais empresas desses segmentos investem acima de 0,25\% do faturamento. Já o número de empresas e a média de investimento são maiores nas grandes empresas, mas a média dos investimentos fica em torno de $0,25 \%$ do faturamento. Segundo a Tabela 4, as empresas de médio e grande portes apresentam maior desenvolvimento de inovação em processo, enquanto um número reduzido de empresas faz inovação em produtos - desenvolvidas por pequenas, médias e grandes empresas.

A inovação nas empresas de nossa amostra difere muito pouco dos dados da PINTEC 2008. No conjunto dos 32 setores industriais, ela identificou que $70 \%$ das empresas fazem inovação em produto e processo; $15 \%$, só em produto, e $12,5 \%$, somente em processo. Nesta pesquisa, a inovação 
em produto e em processo foi realizada por $64,9 \%$ das empresas; desse percentual de inovações, $49 \%$ foi realizado pelas médias-grandes e grandes empresas. Já 10,6\% das empresas inovaram só em produto e $24,5 \%$ só em processo. O maior volume de inovação em processo corrobora a hipótese lançada com base na taxonomia de Pavitt (1984), que o setor de carnes seria dominado por fornecedores. Logo, o desempenho inovador pode ser melhorado quando a empresa estabelece relações com o mercado externo (Arbix; Salerno; De Negri, 2005).

O teste do $\chi^{2}$, em nível de significância de $11 \%$, confirma a existência de relacionamento entre desenvolver inovação em produto e em processo e o porte das empresas da amostra; quanto maior a empresa, maior é a probabilidade de essa ser inovadora. Há diferença nas médias de investimento entre empresas que têm faturamento de até $\mathrm{R} \$ 90$ milhões (pequenas e médias), em relação àquelas que faturam acima desse limite (médias-grandes e grandes), como observado na Tabela 5. De acordo com os resultados, aceita-se a hipótese $\mathrm{H}_{2}$.

Parte das inovações é financiada com recursos públicos, mas poucas empresas da amostra utilizam as facilidades do Sistema Nacional de Inovação. Há pouca cooperação com universidades e institutos de pesquisa para celebrar parcerias em P\&D. Apesar de existir políticas de incentivos à inovação, ainda há pouco interesse das empresas em fi-

Tabela 5_Comparação de médias entre investimento em inovação e porte da empresa

\begin{tabular}{|c|c|c|c|}
\hline Recursos & $\begin{array}{l}\text { Pequena e média1 } \\
\text { (A) }\end{array}$ & $\begin{array}{l}\text { Média-grande } \\
\text { e grande }{ }^{2} \\
\text { (B) }\end{array}$ & $B / A$ \\
\hline $\begin{array}{l}\text { Investimento em } \\
\text { inovação (R\$ mil) }\end{array}$ & 145,96 & $2.405,81$ & 16,5 \\
\hline
\end{tabular}

Obs.: 1- R 2,4 a R 90 milhões; 2- Mais de R\$ 90 milhões (BNDES, 2012) Fonte: Dados da pesquisa de campo dos autores. nanciar projetos de P\&D (Veiga; Rios, 2011). A maioria das inovações foi realizada com recursos próprios. Como os recursos financeiros privados são mais caros que os recursos de agências e bancos oficiais, deveria existir forte demanda, mas isso não foi verificado na amostra. Todas as empresas responderam que são inovadoras. Muitas se referiram à inovação incremental ou a adaptações de processos e à imitação de inovação feita pelos concorrentes. Elas não desenvolveram inovação mais complexa e mais custosa, logo podem não ter usado recursos públicos para financiá-las.

Constatou-se que $1 / 3$ das empresas da pesquisa utilizou algum recurso de programas governamentais. Quanto à participação por tamanho, as médias-grandes e as grandes empresas foram mais ativas em relação às pequenas e às médias empresas. Essa tendência também foi identificada pela PINTEC 2008 (IBGE, 2010). A participação do BNDES foi majoritária na oferta de recursos (23,5\%), seguida dos incentivos fiscais da "Lei do Bem" (5,4\%) e da Finep (2,2\%). Esses resultados mostram que o uso de recursos governamentais para desenvolver inovação, em nossa amostra, não é tão reduzido quando comparado com a pesquisa sobre inovação nas indústrias paulistas (Fapesp, 2010), em que os vários setores utilizam mais de $90 \%$ de recursos próprios para financiar os gastos com P\&D interno e externo, e um dos motivos apontados foi a burocracia que envolve os procedimentos.

Nesta pesquisa, constatou-se que as grandes empresas têm maior facilidade para enfrentar a burocracia e obter recursos financeiros governamentais para apoio à inovação, via BNDES, Finep e incentivos fiscais da "Lei do Bem", além de recursos privados em bancos e Bolsa de Valores, tanto no Brasil como no exterior, na busca de fortalecimento do capital e melhor posição competitiva.

Quanto ao volume de investimentos em inovação, 42,6\% das empresas da pesquisa não ultrapassaram $0,25 \%$ do seu faturamento anual, considerado baixo, quando comparado 
ao índice de 0,64\% levantado na PINTEC 2008, relativo ao setor de transformação da indústria nacional, porém parte é um setor de baixa intensidade tecnológica (De Negri; Alvarenga, 2011). O baixo investimento em inovação também foi verificado por IBGE (2010) na PINTEC 2008 para a indústria de fabricação de produtos alimentícios (0,238\%); os dados encontrados para a indústria corroboram os resultados das pesquisas para a indústria de alimentos verificados por Christensen (1995), Cabral e Traill (2001).

Embora baixo, o valor dos investimentos das empresas exportadoras superou em 15 vezes o valor das não exportadoras. Apesar de existir grande esforço inovador também nas empresas não exportadoras, as empresas exportadoras são as que mais investem em inovação. A presente pesquisa reitera a presença de relação positiva entre inovações e exportações observada no estudo de Arbix, Salerno e De Negri (2005) e Nonnenberg (2011). Nesse sentido, De Negri e Freitas (2004) constataram que as empresas inovadoras elevam em $16 \%$ as suas chances de virem a exportar e que a inovação tecnológica é uma das determinantes das exportações brasileiras.

Para testar a hipótese $\mathrm{H}_{3}$ ("Existe relação positiva entre o apoio financeiro governamental e o desenvolvimento de inovações", primeiramente apresenta-se a relação entre o desenvolvimento de inovações e o apoio governamental e, em seguida, faz-se a comparação de médias do faturamento bruto, exportações e investimentos, entre as empresas que utilizam e as que não utilizam apoio governamental à inovação.

As empresas agroindustriais de carne são, na maioria, exportadoras; as médias-grandes e as grandes empresas representam 94,3\% delas. A maior parte das pequenas e das médias empresas não é exportadora, e faz inovação na busca de maior competitividade no mercado interno. A participação no mercado global expõe a empresa nacional a maior competição internacional. $\mathrm{O}$ aumento da concorrência nesses mercados induz as empresas exportadoras brasileiras à adoção de estratégias modernizantes no processo produtivo e ao desenvolvimento de novos produtos. Mesmo assim, segundo os conceitos da OCDE discutidos por De Negri e Alvarenga (2011), os produtos da indústria de carne são de baixa intensidade tecnológica.

As carnes brasileiras exportadas são produtos padronizados ou commodities. São na maioria exportadas "in natura”, resfriadas ou congeladas, com a competição assentada em preços baixos. A vantagem competitiva da empresa de carne, porém, é garantida pela capacidade de mobilizar conhecimentos, pela habilidade tecnológica e pela experiência para inovar em produtos e em processos, como preconizado por Dalla Costa, Petit e Bittencourt (2008). As exportações desse setor são lideradas por grandes empresas nacionais, que são players mundiais. Também participam médias e pequenas empresas, que acabam desempenhando o papel importante de ampliação da produção e mercado.

A Tabela 6 apresenta as empresas da amostra que afirmaram desenvolver inovação. Apenas 30\% das empresas utilizam recursos e incentivos, enquanto a maioria usa recursos próprios. É interessante notar que, das 10 empresas que mencionaram fazer apenas inovação de produto, metade utiliza o apoio estatal. Isso pode sugerir que os custos e os riscos maiores na inovação de produto estimulem as empresas a buscar apoio financeiro externo. $\mathrm{O}$ teste qui-quadrado foi significativo ao nível de $1 \%$, mostrando que o uso de recursos governamentais é de fundamental importância para o desenvolvimento de inovação nas empresas.

Quanto à novidade, as inovações nas médias-grandes e nas grandes empresas constituíram novidade para os mercados nacional e internacional, ao passo que as inovações nas pequenas e nas médias empresas foram novidade apenas para elas. Na amostra, apenas uma pequena proporção de empresas criou algo diferente para o mercado internacional; a novidade em produto representou 5,3\% e, em processo, 
Tabela 6_Relação entre as empresas que utilizam e as que não utilizam apoio governamental para inovar

\begin{tabular}{|c|c|c|c|c|c|c|}
\hline \multirow[t]{2}{*}{ Tipos de Inovação } & \multicolumn{2}{|c|}{$\begin{array}{l}\text { Pequenas e médias } \\
\text { empresas } \\
\text { Utiliza }\end{array}$} & \multicolumn{2}{|c|}{$\begin{array}{l}\text { Médias-grandes e grandes } \\
\text { empresas } \\
\text { Não utiliza }\end{array}$} & \multicolumn{2}{|l|}{ Total } \\
\hline & Empresas & {$[\%]$} & Empresas & (\%) & Empresas & {$[\%]$} \\
\hline Inovação de produto & 5 & 5,3 & 5 & 5,3 & 10 & 10,6 \\
\hline Inovação de processo & 7 & 7,5 & 16 & 17 & 23 & 24,5 \\
\hline Inovação de produto e processo & 19 & 20,2 & 42 & 44,7 & 61 & 64,9 \\
\hline Total & 31 & 33 & 63 & 67 & 94 & 100 \\
\hline
\end{tabular}

Qui-quadrado $\left(\chi^{2}\right)=10,894$ e $\alpha=0,001$

Fonte: Dados da pesquisa de campo dos autores.

2,1\%. A comparação das médias das empresas de diferentes portes indicou que o investimento em inovação cresce com o aumento do tamanho da empresa. As que mais investem em inovação são as médias-grandes e as grandes, e a maioria delas investe até $0,25 \%$ do faturamento bruto em inovação. As pequenas empresas fazem maior esforço inovador; em termos relativos, a maioria investe mais de 0,25\% do faturamento em inovação. Contudo, os investimentos em inovação das pequenas e das médias empresas são 15,5 vezes menores que os das médias-grandes e das grandes empresas. Esses resultados para o setor agroindustrial de carne estão em conformidade com o estudo de Quadros et al. (2001), Kannebley, Porto e Pazello (2004) e Kannebley (2003).

Conforme a Tabela 7 , as empresas que utilizaram algum tipo de apoio governamental para realizar inovação em produto e em processo apresentaram maior desempenho no faturamento médio ( 5 vezes), no valor médio das exportações (6 vezes) e no valor médio do investimento (4 vezes), em relação às que não utilizaram esses recursos. Apesar de esses resultados não poderem ser diretamente atribuídos ao uso de tais recursos, as empresas que usaram o apoio estatal tiveram resultados positivos em relação às que não o fizeram. Esses resultados são condizentes com os verificados por Ar- bix, Salerno e De Negri (2005), uma vez que as empresas mais inovadoras investem mais na qualificação de funcionários, remuneram melhor a mão de obra e têm melhor desempenho exportador e faturamento. Também corroboram com as conclusões dos estudos de Nonnenberg (2011), que afirma que investir em inovações e decidir exportar estimula a dinâmica que conduz a empresa ao crescimento; Kannebley, Porto e Pazello (2004), que concluem que as exportações ampliam o mercado das empresas, aumentam os retornos e reduzem custos, inclusive na atividade de P\&D; e De Negri (2005), que salienta que as inovações facultam às empresas ofertar produtos de maior nível tecnológico, impactando diferenciadamente os mercados, com reflexos nos seus resultados.

Tabela 7_Comparação de médias entre as empresas que utilizam e as que não utilizam recursos governamentais

\begin{tabular}{l|r|r|l|l}
\multirow{2}{*}{ Recursos } & Média utiliza & $\begin{array}{l}\text { Média } \\
\text { não utiliza }\end{array}$ & \multirow{2}{*}{ A/B } \\
\cline { 2 - 4 } & (A) & (B) & \\
\hline Faturamento bruto (R\$ mil) & $1.858 .900,00$ & $342.218,70$ & 5,4 \\
\hline Exportações (R\$ mil) & $599.383,30$ & $89.602,90$ & 6,7 \\
\hline Investimento em inovação (R\$ mil) & 3.669,70 & $\ldots 59,9$ & 4,3
\end{tabular}

Fonte: Dados da pesquisa de campo dos autores. 
Como observado na Tabela 7 , as empresas que utilizam algum suporte financeiro governamental apresentaram as maiores médias de faturamento bruto, de exportações e de investimentos em inovação. Pode-se inferir que, nesta pesquisa, as empresas que tiveram acesso a recursos governamentais mostraram melhores resultados financeiros, maior desempenho exportador e maiores investimentos em inovação de produtos e processos. Portanto, aceita-se a hipótese $\mathrm{H}_{3}$.

Quanto à estratégia tecnológica, tendo por base questões fechadas, as empresas informaram a reação diante do lançamento de outros produtos pelos rivais, e as respostas permitiram identificar as estratégias de acordo com a classificação de Freeman e Soete (2008), verificando-se na amostra de empresas as principais estratégias tecnológicas utilizadas: defensiva, oportunista e imitativa (Tabela 8). Essas estratégias foram adotadas pela maioria das médias-grandes e das grandes empresas exportadoras, que, sob pressão do mercado internacional, se ajustam às constantes mudanças no padrão de concorrência. Já as pequenas e as médias empresas não exportadoras sofrem menor pressão competitiva; nelas predomina a adoção das estratégias oportunista e tradicional. A estratégia imitativa provavelmente se ajusta a produtos exportados para regiões de igual ou menor desenvolvimento econômico como América Latina e África.
Apenas uma pequena proporção de empresas (5,3\%) adota a estratégia ofensiva. Esta estratégia é característica de empresas líderes, que têm visão de longo prazo, visam maiores lucros; essas fazem pesquisas para desenvolver novos produtos e constantemente lançam produtos no mercado. As empresas com ação exportadora mais ativa utilizam-se da estratégia ofensiva, que foram seis vezes superiores ao valor exportado pelas empresas com estratégias defensivas e imitativas. No setor brasileiro de carne, as principais empresas que adotam essa estratégia são Minerva, BRF, Marfrig e JBS (Carvalho, 2011). A aquisição de empresas estrangeiras contribuiu para aumentar o lançamento de produtos.

A estratégia defensiva é a mais adotada pelas empresas da amostra $(53,2 \%)$ e está associada à diferenciação de produto e ao menor risco (Tabela 8). Tais empresas não querem correr o risco de ser as primeiras a inovar, mas também não querem ser deixadas para trás em relação à tecnologia; procuram, então, aprender com os erros dos pioneiros e se adaptar a mudanças introduzidas pelos concorrentes.

A estratégia oportunista é adotada por 20,3\% das empresas de carne. É empregada pelas empresas empenhadas em suprir mercados que surgem temporariamente ou em oportunidades decorrentes de rápida transformação do mercado e não necessitam de elevados investimentos em inovação. Conforme Tigre (2006), o mercado de carne tem passado por cons-

Tabela 8_Estratégias tecnológicas e o porte das empresas

\begin{tabular}{|c|c|c|c|c|c|c|c|c|c|c|}
\hline \multirow{2}{*}{ Estratégias } & \multicolumn{10}{|l|}{ Empresas } \\
\hline & Pequena & $\%$ & Média & $\%$ & Média-grande & $\%$ & Grande & $\%$ & Total & $\%$ \\
\hline Defensiva & 4 & 23,5 & 5 & 50 & 19 & 67,9 & 22 & 56,4 & 50 & 53,2 \\
\hline Oportunista & 8 & 47 & 3 & 30 & 4 & 14,3 & 4 & 10,3 & 19 & 20,2 \\
\hline Imitativa & 0 & 0 & 1 & 10 & 2 & 7,1 & 10 & 25,6 & 13 & 13,8 \\
\hline Tradicional & 4 & 23,5 & 1 & 10 & 1 & 3,6 & 1 & 2,5 & 7 & 7,4 \\
\hline Ofensiva & 1 & 6 & 0 & 0 & 2 & 7,1 & 2 & 5,2 & 5 & 5,3 \\
\hline Total & 17 & 100 & 10 & 100 & 28 & 100 & 39 & 100 & 94 & 100 \\
\hline
\end{tabular}

Fonte: Dados da pesquisa de campo dos autores. 
tante transformação resultante de aquisições, falências e reestruturação organizacional das empresas, e fez surgir nichos de mercados que são aproveitados pelas empresas menores.

Para testar a hipótese $\mathrm{H}_{4}$ ("Existe relação positiva entre a estratégia tecnológica ofensiva da empresa e a sua ação exportadora”) foram realizadas análise de frequência das estratégias tecnológicas pelo porte das empresas e comparação de médias para ação exportadora. Dentre as seis estratégias tecnológicas definidas por Freeman e Soete (2008), as que efetivamente geram outros produtos são as estratégias ofensiva, defensiva e oportunista.

Conforme a Tabela 8,74 empresas adotam uma das três estratégias, com destaque para a estratégia defensiva. As pequenas empresas são as que mais utilizam a estratégia oportunista, provavelmente explorando mercados locais desprezados pelas empresas maiores. As médias-grandes e as grandes adotam preferencialmente a estratégia defensiva, que também consiste de grande esforço inovador, porém é cautelosa quanto à introdução de (novos) produtos no mercado, esperando a ação das líderes, que adotam a estratégia ofensiva.

A Tabela 9 apresenta os resultados da comparação de médias do faturamento das empresas exportadoras e das não exportadoras em relação à estratégia tecnológica adotada. Verifica-se que a maioria das médias-grandes e das grandes empresas são empresas exportadoras; já, dentre as pequenas e as médias empresas, poucas exportam.

$\mathrm{O}$ teste $\mathrm{t}$ foi usado para o comparativo entre as médias do faturamento das empresas exportadoras e do das não exportadoras e mostrou não significativo ao nível de $5 \%$, ou seja, rejeita a hipótese de igualdade de médias. Com isso, podemos afirmar que as médias do faturamento das empresas exportadoras são maiores que as do faturamento das não exportadoras. Também podemos supor que as empresas exportadoras são dotadas de maior capacidade para atuar no mercado competitivo internacional.
Tabela 9_Comparação de médias do faturamento entre as estratégias e a ação exportadora

\begin{tabular}{|c|c|c|c|}
\hline Estratégias & $\begin{array}{l}\text { Média exportadora } \\
\text { (A) }\end{array}$ & $\begin{array}{l}\text { Média não } \\
\text { exportadora } \\
\text { (B) }\end{array}$ & $A / B$ \\
\hline Ofensiva ( $\mathrm{R} \$$ mil) & 6.555.910,51 & 780,53 & $8.405,10$ \\
\hline Defensiva (R\$ mil) & 808.230,39 & $35.824,33$ & 22,5 \\
\hline Oportunista (R\$ mil) & $624.442,81$ & $14.231,44$ & 43,9 \\
\hline Imitativa (R\$ mil) & 872.884,58 & $86.021,31$ & 10,1 \\
\hline Tradicional (R\$ mil) & $346.766,67$ & 1.307,52 & 265,2 \\
\hline
\end{tabular}

Teste $\mathrm{t}=1,607$ e $\alpha=0,183$

Fonte: Dados da pesquisa de campo dos autores.

As empresas exportadoras que obtiveram o menor resultado dentre as empresas exportadoras referem-se às que adotam estratégia tradicional. $\mathrm{O}$ bom desempenho das empresas exportadoras que utilizam estratégia imitativa sugere que elas exportam para países em desenvolvimento de menor renda (América Latina e África). A única estratégia que se destaca, porém, em termos de maior valor de exportações, é a ofensiva, apesar de representar 5,3\% da amostra. As estratégias defensivas e as imitativas apresentam resultados similares, não diferenciáveis em termos estatísticos, mas a estratégia ofensiva se diferencia das demais. Com isso, aceita-se a hipótese $\mathrm{H}_{4}$.

Quanto ao tipo de inovação em produto e em processo (Tabela 10), os resultados da pesquisa mostraram que as inovações se diferenciam pelo porte das empresas, sendo mais realizadas as inovações em produto e em processo, simultaneamente; poucas utilizam inovação só de produto. Também as inovações em produto e em processo são mais adotadas pelas médias-grandes e pelas grandes empresas. Esses resultados coincidem com os de Quadros et al. (2001), Kannebley, Porto e Pazello (2004) e Gomes e Kruglianskas (2009), segundo os quais as grandes empresas agroindustriais 
Tabela 10 Frequência da novidade por tipo de inovação

\begin{tabular}{|c|c|c|}
\hline Tipos de inovação & Empresas & {$[\%]$} \\
\hline Inovação de produto & 10 & 10,6 \\
\hline Inovação de processo & 23 & 24,5 \\
\hline Inovação de produto e processo & 61 & 64,9 \\
\hline Total & 94 & 100 \\
\hline
\end{tabular}

Fonte Dados da pesquisa de campo dos autores.

fazem maior uso de inovação, e o número de empresas que realizam inovação em produto e em processo, em conjunto é superior ao das que adotaram apenas um tipo de inovação. As empresas da amostra, mesmo as que adotam o modelo de inovação fechada, acabam por se relacionar com outros agentes externos e trocam informações que contribuem para a tomada de decisão sobre inovação, conforme sugerem Mowery e Rosenberg (2005).

Para testar a hipótese $\mathrm{H}_{5}$ ("A inovação nas empresas agroindustriais de carne é mais frequente em processos do que em produtos"), observou-se a frequência com que as empresas fazem inovação em produtos e em processos na Tabela 10. As empresas que inovaram apenas em processos somam $24,5 \%$ dos casos, enquanto as que fizeram inovação em produtos somam apenas 10,6\% dos casos. Observa-se que as empresas tiveram dificuldade em entender as diferenças dos tipos de inovação em produto e em processo, visto que, em muitos casos, a compra de equipamentos mais modernos, automaticamente, permite a fabricação de produtos distintos. Assim, podemos inferir que o pressuposto é aceito.

Para testar a hipótese H6 ("As empresas mais inovadoras se apoiam mais em fontes externas de inovação"), foi realizada análise das fontes e dos tipos de inovação praticados pelas empresas da amostra. A Tabela 11 mostra que as empresas que fazem inovação em processo e produto utilizam as fontes externas de inovação relacionadas a fornecedores, a clientes e à participação em conferências, feiras e exposições.

Conforme a Tabela 11, as fontes externas de inovação foram classificadas em três grupos, considerando a frequência total dos tipos por fonte de inovação e agrupadas pela proximidade das fontes (fontes $1,2 \mathrm{e} 3$; fontes $4,5 \mathrm{e} 6$; e fontes $7 \mathrm{e} 8$ ). $\mathrm{O}$ teste $\mathrm{V}$ de Cramer mostrou que as fontes externas de ino-

Tabela 11_Frequência da utilização de fontes externas por tipo de inovação

\begin{tabular}{|c|c|c|c|c|c|c|c|c|}
\hline Fontes & Produto & {$[\%]$} & Processo & {$[\%]$} & $\begin{array}{l}\text { Produto e } \\
\text { processo }\end{array}$ & {$[\%]$} & Total & {$[\%]$} \\
\hline 1. Fornecedores & 9 & 7,5 & 17 & 14,2 & 55 & 45,8 & 81 & 67,5 \\
\hline 2. Clientes ou consumidores & 10 & 8,3 & 14 & 11,7 & 46 & 38,3 & 70 & 58,3 \\
\hline $\begin{array}{l}\text { 3. Participação em conferências, } \\
\text { feiras e exposições }\end{array}$ & 5 & 4,2 & 17 & 14,2 & 46 & 38,3 & 68 & 56,7 \\
\hline $\begin{array}{l}\text { 4. Empresas de consultoria e } \\
\text { consultores independentes }\end{array}$ & 2 & 1,7 & 10 & 8,3 & 29 & 24,2 & 41 & 34,2 \\
\hline 5. Concorrentes & 3 & 2,5 & 3 & 2,5 & 15 & 12,5 & 21 & 17,5 \\
\hline 6. Universidades e institutos de pesquisa & 1 & 0,8 & 1 & 0,8 & 18 & 15 & 20 & 16,7 \\
\hline 7. Redes de informações informatizadas & 1 & 0,8 & 0 & 0 & 8 & 6,7 & 9 & 7,5 \\
\hline $\begin{array}{l}\text { 8. Licenças e aquisições de patentes e } \\
\text { know-how }\end{array}$ & 0 & 0 & 1 & 0,8 & 7 & 5,8 & 8 & 6,7 \\
\hline
\end{tabular}

Fonte: Dados da pesquisa de campo dos autores. 
vação exerceram moderada influência no desenvolvimento de inovação nas empresas da amostra. $\mathrm{O}$ resultado do teste de Cramer para o primeiro e o terceiro grupos indicou haver associação entre as inovações desenvolvidas pelas empresas ao nível de significância de $10 \%$ e valor de 0,218 , enquanto 0 segundo grupo, com nível de significância de $20 \%$ e valor de 0,214, indicou ser fraca essa associação.

Das informações da Tabela 11, subentende-se que a maior parte das inovações desse setor é realizada pela aquisição de máquinas e equipamentos (fornecedores). A atualização de conhecimentos sobre novos equipamentos e novas tecnologias de produto e processo é realizada pela participação em conferências, feiras e exposições. As universidades e os institutos de pesquisa, assim como o acesso a licenças, aquisições de patentes e know-how, como fontes de desenvolvimento de conhecimento para a inovação, foram pouco acionados pelas empresas, confirmando a dependência de conhecimentos desenvolvidos pelos setores produtores de máquinas e equipamentos, matérias-primas, insumos biológicos e medicamentos.

Empresas de consultoria/consultores independentes foram utilizadas por um terço das empresas. Uma pequena parte das empresas informou fazer cooperação com universidades, institutos de pesquisa e concorrentes, além de participar de redes de informações informatizadas e obter licenças, patentes e know-how. Pode-se inferir que as empresas mais inovadoras realizam atividades de P\&D interna e complementam seus esforços com fontes externas, permitindo aceitar a hipótese H6. Os resultados corroboram Chesbrough (2003) e Sbragia et al. (2006), já que as empresas passaram a considerar as competências externas na sua formulação de estratégias para desenvolver inovação. As fontes externas de informações para inovar foram agrupadas em três conjuntos: a) fornecedores, clientes e participação em conferências, feiras e exposições; este foi o grupo de maior contribuição
(77,6\%) para a inovação nas empresas; b) empresas de consultoria, concorrentes e universidades e institutos de pesquisa contribuíram com 29,1\% para o desenvolvimento de inovação; c) redes de informações informatizadas, e licenças, aquisições de patentes e know-how contribuíram com apenas 6\%.

O principal grupo de fontes externas de informações parece indicar que as inovações, na maioria das empresas do setor, são orientadas pelo mercado e direcionadas para o desenvolvimento de inovação em processo. Já o segundo grupo tende a voltar-se para inovação de produto, principalmente pela presença de universidades e institutos de pesquisa. $\mathrm{O}$ terceiro grupo foi considerado de menor importância. As fontes externas de informações para inovação também foram mencionadas por Sbragia et al. (2006), com obtenção de resultados percentuais menores do que os verificados nesta pesquisa. Também diferem da PINTEC 2008, se bem que os resultados indicaram que os fornecedores, as feiras e as exposições foram os responsáveis pela inovação em processo, o que confirma ser o setor dominado por fornecedores, conforme a taxonomia de Pavitt (1984). A maioria das empresas faz inovação incremental, utilizando-se das informações de clientes e fornecedores, as quais não circulam livremente na internet.

\section{- Benefícios da inovação}

O impacto da inovação nas empresas pode ser mais facilmente percebido quando a inovação é radical, por provocar ruptura no processo produtivo, dando origem a um novo processo ou a um novo produto. Entretanto, a inovação incremental é pouco percebida, por gerar mudanças gradativas, que tornam o processo produtivo mais eficiente (Lemos, 2000). Os benefícios da inovação podem ser deduzidos dos resultados e das mudanças de comportamento dos fatores internos e da relação com o mercado (De Negri; Salerno; 
Castro, 2005). As empresas da amostra avaliaram os benefícios derivados da adoção de inovação, classificando-os por importância.

O aumento da participação de mercado e da produtividade na empresa foi o benefício mais importante para a maioria das empresas pesquisadas, ao passo que o efeito benéfico da aproximação com as universidades e os institutos de pesquisa só foi mencionado pelas empresas que efetivamente buscaram essa parceria $(8,9 \%)$, e abriu caminho para o desenvolvimento conjunto de inovações (Tabela 12).

Esse resultado indica pouca importância atribuída a essas instituições como fonte de geração de tecnologia a ser utilizada pelas empresas, que, além de atuarem voltadas para as suas atividades internas, não veem à universidade e os institutos de pesquisa como potenciais parceiros para o seu desenvolvimento tecnológico.
Os benefícios da inovação dos itens 3 a 8 foram avaliados como de média à alta importância pela maioria das empresas pesquisadas. As empresas que declararam ser muito alta a importância do aumento da participação de mercado e do aumento da produtividade representam mais de $20 \%$ da amostra. Verificou-se um primeiro grupo de benefícios formado pelos fatores avaliados como de alta a muito alta importância da inovação para o aumento da participação no mercado $(74,5 \%)$ e da produtividade na empresa $(65,7 \%)$ (Nonnenberg, 2011). O segundo grupo é formado pelos fatores avaliados como de média e alta importância da inovação para acesso a novos mercados, ampliação do portfólio de produtos e aumento da flexibilidade na produção da empresa. $\mathrm{O}$ esforço empresarial para introduzir inovação visa buscar resultados e melhor posicionamento da empresa no mercado.

Tabela 12_Frequência dos benefícios decorrentes da introdução de inovação [\%]

\begin{tabular}{|c|c|c|c|c|c|c|c|c|}
\hline Benefícios da inovação & Empresas & Não relevante & 1 & 2 & 3 & 4 & 5 & $4+5$ \\
\hline 1. Aumentou a participação de mercado & 94 & 3,9 & 2,0 & 2,0 & 17,6 & 52,0 & 22,5 & 74,5 \\
\hline 2. Aumentou a produtividade da empresa & 94 & 1,0 & 1,0 & 5,9 & 26,5 & 45,1 & 20,6 & 65,7 \\
\hline 3. Permitiu o acesso a novos mercados & 94 & 6,9 & 2,9 & 7,8 & 28,4 & 43,1 & 10,8 & 53,9 \\
\hline $\begin{array}{l}\text { 4. Ampliou a gama de } \\
\text { produtos ofertados ao mercado }\end{array}$ & 94 & 2,9 & 2,0 & 7,8 & 35,3 & 41,2 & 10,8 & 52,0 \\
\hline 5. Aumentou a flexibilidade na produção & 94 & 1,0 & 3,9 & 16,7 & 30,4 & 37,3 & 10,8 & 48,1 \\
\hline $\begin{array}{l}\text { 6. Reduziu o tempo de desenvolvimento e } \\
\text { chegada do produto no mercado }\end{array}$ & 94 & 2,0 & 2,0 & 14,7 & 38,2 & 36,3 & 6,9 & 43,2 \\
\hline 7. Aumentou as exportações & 72 & 29,4 & 0 & 2,9 & 24,5 & 27,5 & 15,7 & 42,2 \\
\hline $\begin{array}{l}\text { 8. Facilitou a adequação às normas } \\
\text { nacionais e internacionais }\end{array}$ & 94 & 5,9 & 2,0 & 11,8 & 31,4 & 39,2 & 9,8 & 39,0 \\
\hline $\begin{array}{l}\text { 9. Facilitou a aproximação da empresa às } \\
\text { universidades e aos institutos de pesquisa }\end{array}$ & 94 & 22,5 & 23,5 & 28,4 & 16,7 & 6,9 & 2,0 & 8,9 \\
\hline
\end{tabular}

Escala: Não relevante; 1- Muito baixa; 2- Baixa; 3- Média; 4- Alta; 5- Muito alta importância.

Fonte: Dados da pesquisa de campo dos autores. 


\section{5_Notas conclusivas}

O estudo analisou uma amostra de 94 empresas do setor agroindustrial de carne de frango, suína e bovina no ano de 2010. $O$ investimento em inovação mostrou-se baixo, relativamente a outros setores, concentrando-se na faixa entre $0,2 \%$ e $2 \%$ do faturamento bruto anual. A maioria das empresas média-grande e grandes é inovadora (65\%), combina inovações em produto e em processo, enquanto parte das empresas médias e pequenas faz inovações ou produto ou processo, $10,5 \%$ e $24,5 \%$, respectivamente.

Poucas empresas conheciam e utilizavam os programas governamentais de apoio à inovação. Dos recursos destinados a investimento em inovação, apenas um terço é de fonte governamental, proveniente do BNDES, da Finep e de incentivos fiscais da "Lei do Bem". Esses recursos foram utilizados, principalmente, pelas grandes empresas, que produziram novidade para o mercado nacional e, mais raramente, para o mercado internacional.

A estratégia tecnológica mais utilizada pelas empresas da amostra é a defensiva, e, em ordem de preferência, as empresas adotaram as estratégias oportunistas, imitativas e ofensivas. As grandes empresas se diferenciam das pequenas, das médias e das médias-grandes por optarem pela estratégia ofensiva, mas, como não conseguem manter a liderança o tempo todo, alternam com a estratégia defensiva, enquanto parte das menores empresas adota estratégia defensiva, e outras, a estratégia oportunista, atuando em mercado que não interessa às grandes empresas.

A decisão de inovar nessas empresas tem privilegiado a adoção de novas tecnologias de processo que levam ao desenvolvimento de outros produtos, mas a ênfase é na adoção de novos processos produtivos. Como essa decisão envolve riscos e incertezas, as empresas têm dificuldade para realizar inovação, embora os dirigentes reconheçam que elas são importantes na geração de futuros resultados. Uma das formas de superar a carência é recorrer a parcerias com fornecedores ou com universidades e institutos de pesquisa. No entanto, o uso desse mecanismo para desenvolver inovação e efetivar a transferência de tecnologias ainda é baixo.

A inovação promoveu substancial melhoria nos indicadores de mercado e nas condições de atendimento a novas demandas. Os benefícios da inovação considerados de alta e muito alta importância identificam-se com o aumento da participação no mercado e o aumento da produtividade da empresa. Verificou-se que o tamanho é importante, e a inserção externa também está relacionada a maiores valores gastos em inovação, embora esta seja de natureza incremental.

A inovação tecnológica é um fator determinante das exportações brasileiras nesse setor, apesar de o país ter perdido posição mundial nessa área. As empresas inovadoras têm chances maiores de inserção no mercado internacional do que as não inovadoras. Observa-se que o desenvolvimento próprio de inovação aumenta a possibilidade de uma empresa ser exportadora em comparação à adoção de inovação por difusão de tecnologias já existentes no mercado brasileiro. A inovação de produto tem maior influência sobre a empresa exportadora do que a inovação em processos produtivos mais eficientes, embora os fatores não relacionados a preço, como qualidade e marketing, tenham assumido papel cada vez mais importante na determinação dos fluxos internacionais de comércio.

A competição externa por inovação e/ou diferenciação de produto tem sido a ferramenta mais utilizada pelas empresas exportadoras brasileiras de carne. A inovação tecnológica vem contribuindo para o aumento da competitividade dessas empresas, sustentada pelo crescimento da produção, pela expansão dos mercados, pelos ganhos efetivos da produtividade interna e pelo notável desempenho exportador. 
ANDREASSI, T. Gestão da inovação tecnológica. São Paulo: Thomson Learning, 2007.

ARBIX, G.; SALERNO, M. S.; DE NEGRI, J. A. O impacto da internacionalização com foco na inovação tecnológica sobre as exportações das firmas brasileiras. Revista de Ciências Sociais, Rio de Janeiro, v. 48, n. 1, p. 395-442, 2005.

AREND, M.; CARIO, S. A. F; ENDERLE, R. Instituições, inovações e desenvolvimento econômico. Pesquisa \& Debate. Revista do Programa de Estudos PósGraduados em Economia Política,

v. 23, n. 1, p. 110-133, 2012.

BNDES - Banco Nacional de

Desenvolvimento Econômico e Social. Inovação. Disponível em: <http://www.bndes.gov.br/ SiteBNDES/bndes/bndes_pt/ Areas_de_Atuacao/Inovacao/ index.html >. Acesso em: 20 set. 2011.

CABRAL, J. E. O.; TRAILL. B. W. Determinants of a firm's likelihood to innovate and intensity of innovation in the Brazilian food industry. Chain and Network Science. v. 1, n. 1, June 2001. Disponível em: <http:// wageningenacademic.metapress. com/content/3q95456662865652/>. Acesso em: 14 jun. 2010.
CAPITANIO, F.; COPPOLA, A.; PASCUCCI, S. Indications for drivers of innovation in the food sector. British Food Journal, v. 111, n. 8, p. 820-838, 2009.

CARVAlHO, T. B. Produção de carnes e mercados. In: FÓRUM TENDÊNCIAS E INOVAÇÕES PARA AS INDÚSTRIAS DE CARNE, 1., 2011, Piracicaba. Anais... Piracicaba: Centro de Estudos Avançados em Economia Aplicada (CEPEA). Piracicaba: CEPEA/ESALQ/USP. 24/08/2011.

CHESBROUGH, H. W. The era of open innovation. MIT Sloan Management Review, v. 44, n. 3 , p. $35-42,2003$.

CHRISTENSEN, J. F. Asset profiles for technological innovation. Research Policy, v. 24, p. $727-745,1995$.

CONCEIÇ̃̃O, O. A. C. A dimensão institucional do processo de crescimento econômico: Inovações e mudanças institucionais, rotinas e tecnologia social. Economia e Sociedade, Campinas, v. 17, n. 1 (32), p. 85-105, abr. 2008.
DALLA COSTA, A. J.; PETIT, P.; BITTENCOURT, M. V. L. Innovations, technologies and economic development: An evolutionary view of the Brazilian poultry industry and its firms. In: RESEARCH WORKSHOP ON INSTITUTIONS AND ORGANIZATIONS, III., 2008, São Paulo. Anais... São Paulo: USP, IBMEC and FGV-SP, Oct. 13-14, 2008.

DE NEGRI, F. Inovação tecnológica e exportações das firmas brasileiras. In: ENCONTRO DA ANPEC, 33., 2005, Rio de Janeiro. Anais... Rio de Janeiro: ANPEC, 2005. Disponível em: <http://www.anpec.org.br/ encontro2005/artigos/A05A100. pdf $>$. Acesso em: 21 mar. 2011.

\section{DE NEGRI, F.; ALVARENGA G.} V. A primarização da pauta de exportações no Brasil: Ainda um dilema. Boletim Radar, IPEA, n. 13, p. 7-14, abr. 2011.

\section{DE NEGRI, J. A.; FREITAS, F.} Inovação tecnológica, eficiência de escala e exportações brasileiras. Brasília, IPEA, Texto para Discussão n. 1044, set. 2004.
DE NEGRI, J. A.; SALERNO, M. S.; CASTRO, A. B. Inovações, padrões tecnológicos e desempenho das firmas industriais brasileiras. In: DE NEGRI, J. A.; SALERNO, M. S. (Orgs.). Inovações, padrões tecnológicos e desempenho das firmas industriais brasileiras. Brasília: IPEA, 2005. p. 5-46.

DOSI, G. Mudancas técnicase transformação industrial: A teoria e a aplicação na indústria de semicondutores. Campinas: Ed. Unicamp, 2006. (Clássicos da Inovação).

DOSI, G.; NELSON, R. R. An introduction to evolutionary theories in economics. Journal of Evolutionary Economics, v. 4, n. 3, p. 153-172, 1994

FAO, Organização das Nações Unidas para Agricultura e Alimentação. FAOSTAT. Disponível em: $<$ http:// faostat.fao.org/site/535/default. aspx\#ancor $>$. Acesso em: 19 jun. 2010.

FAPESP,Fundação de Amparo à Pesquisa de São Paulo. Indicadores de ciência, tecnologia e inovação em São Paulo 2010. São Paulo: FAPESP, 2011.. Disponível em: $<$ http:// www.fapesp.br/indicadores2010>. Acesso em: 22 ago. 2011 
FINEP - Fundos setoriais.

Disponível em: <http:// www.finep.gov.br/fundos setoriais/fundos_setoriais_

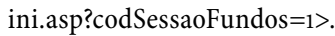
Acesso em: 20 set. 2011.

FREEMAN, C.; SOETE, L. As inovações e as estratégias das firmas. In: CAMPOS, A. L. S.; CosTA, J. O. P. (Trad.). A economia da inovação industrial. Campinas: Ed. Unicamp, 2008. (Clássicos da Inovação).

GOMES, C. F.; KRUGLIANSKAS, I. A influência do porte no comportamento inovador da empresa. Revista de Administração e Inovação - RAI, São Paulo, v. 6, n. 2, p. 5-27, 2009.

GRIZENDI, E. Manual de orientação geral sobre inovações. Ministério das Relações Exteriores. Projeto No BRA 07/017. Programa das Nações Unidas para o Desenvolvimento - PNUD, 2011. Disponível em: <http:// www.finep.gov.br/dcom/ manualinovacao.pdf $>$. Acesso em: 20 set. 2011.

IBGE - Instituto Brasileiro de Geografia e Estatística. Banco de dados do sistema Aliceweb. Disponível em: <http://aliceweb. desenvolvimento.gov.br/default. asp>. Acesso em: 17 abr. 2011.

IBGE - Instituto Brasileiro de Geografia e Estatística. Pesquisa de inovação tecnológica: 2008. Rio de Janeiro: IBGE, 2010. Disponível: em <http://www.pintec.ibge.gov. br/downloads/PUBLICACAO/ Publicacao\%20PINTEC\%202008. pdf>. Acesso em: 9 mar. 2011.
KANNEBLEY, S. Jr.

Características das firmas inovadoras no estado de São Paulo: Uma análise empírica a partir da Fapesp. FEA/USP - Série Economia, 2003. (Textos para discussão TD-E 40).

KANNEBLEY, S. Jr.; PORTO, G. S.; PAZELLO, E. T. Inovação na indústria brasileira: Uma análise a partir da PINTEC. Revista Brasileira de Inovação, v. 3, n. 1, jan./jun. 2004.

LALL, S. A mudança tecnológica e a industrialização nas economias de industrialização recente da Ásia: Conquistas e desafios. In: Tecnologia, aprendizado e inovação: As experiências das economias de industrialização recente. Campinas: Ed. Unicamp, 2005. p. 25-100 (Clássicos da Inovação).

LEMOS, C. Inovação na era do conhecimento. Ciência, Tecnologia \& Sociedade Parcerias Estratégicas, n. 8, p. 157179, maio 2000. Disponível em: <http://www.cgee.org.br/ arquivos/pe_08.pdf $>$. Acesso em: 21 jan. 2011.

\section{MALERBA, F.; ORSENIGO,}

L. Schumpeterian patterns of innovation are technologyspecific. Research Policy, v. 25 , p. $451-478,1996$.

MOWERY, D. C.; ROSENBERG, N. Trajetória da inovação: A mudança tecnológica nos Estados Unidos da América no século XX.

Campinas: Ed. Unicamp, 2005. (Clássicos da Inovação).
NELSON, R.; WINTER, S. An evolutionary theory of economic change. Cambridge, Mass.: Harvard University Press, 1982.

NONNENBERG, M. J. B. Exportações e inovação: Uma análise para a América Latina e Sul - Sudeste da Ásia. Rio de Janeiro: IPEA, fev. 2011. (Texto para discussão N. 1579). Disponível em: <http:// www.ipea.gov.br/sites/000/2/ publicacoes/tds/TD_1579_Web. pdf $>$. Acesso em: 22 mar. 2011.

OCDE. Manual de 0slo: Proposta de diretrizes para coleta e interpretação de dados sobre inovação tecnológica. Finep: tradução em português, 2005.

PAVITT, K. Sectorial patterns of technical change: Towards a taxonomy and a theory. Research Policy, vol. 13, n. 6, p. 343-373, 1984.

POSSAS, Mario Luiz.

Economia evolucionária neosschumpeteriana: Elementos para uma integração micromacrodinâmica. Estudos Avançados, v. 22, n. 63, p. 281-305, 2008.

QUADROS, R.; FURTADO, A.; BERNARDES, R.; FRANCO, E.

Technological innovation in Brazilian industry: An assessment based on the São Paulo innovation survey. Technological Forecasting and Social Change, v. 67, n. 2-3, p. 203-219, jun. 2001.

\section{RODRIGUES, I.; VASCONCELOS,}

E. P. G.; SBRAGIA, R.

Internacionalização de $P \& D$ na Petrobras. XII Seminário LatinoIberoamercano de Gestion TecnológicaALTEC (CD-ROM). Buenos Aires, Argentina, 2007.
SANTINI, G. A. Dinâmica tecnológica da cadeia de frango de corte no Brasil: Análise dos segmentos de insumos e processamentos. 2006. 235 f. Tese (Doutorado em Engenharia de Produção) - Centro de Ciências Exatas e de Tecnologia, Universidade Federal de São Carlos, São Carlos, 2006.

SBRAGIA, R.; STAL, E.; CAMPANÁRIO, M. A.; ANDREASSI, T. Inovação: Como vencer esse desafio empresarial. São Paulo: Clio, 2006.

SCHUMPETER, J. Capitalismo, socialismo e democracia. Rio de Janeiro: Zahar Editores, 1984.

SIEGEL, S.; CASTELLAN JR., N. J. 2. ed. Estatística não-paramétrica para Ciências do Comportamento. Porto Alegre, Artmed, 2006.

STAL, E. Inovação tecnológica, sistemas nacionais de inovação e estímulos governamentais à inovação. In: MOREIRA. D. A.; QUEIROZ, A. C. S. (Coord.). Inovação organizacional e tecnológica. São Paulo: Thomson Learning, 2007. Capítulo 2. p. 23-53.

STAL, E.; SEREIA, V. J.; SILVA, R. S. Estratégias de internacionalização do setor agroindustrial brasileiro de carnes: Exportação ou investimento direto no exterior? Future Studies Research Journal: Trends and Strategies, v. 2, n. 2, p. 132-161, out./dez. 2010. 
STAL, E; CAMPANÁRIO, M.

A. Indicadores de inovação tecnológica em empresas

brasileiras internacionalizadas.

In: SIMPÓSIO DE GESTÃO DA

INOVAÇÃO TECNOLÓGICA, 26,

2010, Vitória. Anais... Vitória:

ANPAD (CD-ROM) 2010.

TIDD, J.; BESSANT, J.; PAVITT, K.

Gestão da Inovação. 3. ed. Porto

Alegre: Bookman, 2008.

TIGRE, P. B. Gestão da Inovação:

A economia da tecnologia no

Brasil. 3. ed. Rio de Janeiro:

Campus, 2006.

VEIGA, P. M.; RIOS, S. P. Inovação:

Política e desempenho das

E-mail de contato dos autores:

sereia@uel.br

eva.stal@terra.com.br

mgabardo@uel.br

empresas. Centro de Estudos de

Integração e Desenvolvimento.

Rio de Janeiro: CINDES, 2011.

Artigo recebido em dezembro de 2013 e aprovado em setembro de 2014. 